\title{
Loss of immunoreactivity for RTI40, a type I cell-specific protein in the alveolar epithelium of rat lungs with bleomycin-induced fibrosis
}

\author{
R. Koslowski*, L.G. Dobbs+, K-W. Wenzel*, D. Schuh**, M. Müller**, M. Kasper***
}

Loss of immunoreactivity for RTI40, a type I cell-specific protein in the alveolar epithelium of rat lungs with bleomycin-induced fibrosis. R. Koslowski, L.G. Dobbs, K-W. Wenzel, D. Schuh, M. Müller, M. Kasper. (OERS Journals Ltd 1998.

ABSTRACT: After lung injury, the epithelial cells lining the alveolar surface in rat lung show an altered distribution of several membrane proteins.

Pulmonary fibrosis was induced by intratracheal administration of bleomycin into the lung of rats and the distribution of RTI40, a recently detected alveolar epithelial type I cell antigen, was examined, as well as the relationship between RTI40 and a type I cell-specific antigen recognized by the monoclonal antibody MEP-1 and the type I cell-binding lectin Bauhinia purpurea in serial sections and double stainings.

Loss of RTI40 protein was observed in fibrotic lungs, particularly in areas with obliteration of alveoli. Pre-embedding immunoelectron microscopy confirmed this observation by detection of RTI40 protein in the alveolar lumen. Western blot analysis revealed elevated levels of RTI40 in the bronchoalveolar fluid of bleomycin-treated rats with a maximum at day 7 after treatment. Twenty-eight days after bleomycin application, the bronchoalveolar fluid contained three times the amount of RTI40 $\mathrm{mg}$ protein $^{-1}$ of control lungs, as determined by semiquantitative dot blot.

These results suggest RTI40 as a tool for the evaluation of alveolar epithelial type I cell behaviour during re-epithelialization processes.

Eur Respir J 1998; 12: 1397-1403.
Institutes of *Physiological Chemistry, **Pathology and ***Anatomy, Dresden University of Technology, Dresden, Germany. +Cardiovascular Research Institute and Dept of Medicine, University of California, San Francisco, USA.

Correspondence: R. Koslowski, Institute of Physiological Chemistry, Medical Faculty Carl Gustav Carus, Dresden University of Technology, Karl-Marx-Str. 3, D-01109 Dresden, Germany

Fax: 493518832875

Keywords: Bleomycin, epithelium, fibrosis, lung, type I cell

Received: October 281997

Accepted after revision August 41998

Supported by the Bundesministerium für Bildung, Wissenschaft, Forschung und Technologie (01ZZ5904) and in part by Grants HL-24075 and HL-57426 from the US National Heart, Lung and Blood Institute.
The rat alveolar epithelium comprises three different epithelial cell types: the large squamous type I cells, the cuboidal type II pneumocytes and the bottle-shaped alveolar brush (type III) cells. Various biochemical markers have been used to distinguish type I from type II cells. Most of these markers are not unique for either cell type, but are helpful in defining the different phenotypes of type I and type II cells. Type II pneumocytes may be distinguished from type I cells by their cytokeratin pattern, by the presence of certain enzymes (e.g. alkaline phosphatase, carbonic anhydrase II, carbonyl reductase, protein disulphide isomerase and catalase), by the presence of surfactant apoproteins (SP-A, SP-B, SP-C and SP-D) and by different lectin binding (Maclura pomifera agglutinin (MPA)) (reviewed in [1, 2]). Alveolar brush (type III) cells lack surfactant proteins and are selectively decorated with cytokeratin 18- and villin-specific antibodies [3, 4]. Type I pneumocytes, in contrast to type II pneumocytes, bind various lectins (Lycopersicon esculentum agglutinin (LEA), Erythrina cristagalli agglutinin (ECA) or Bauhinia purpurea agglutinin (BPA)) [5-7], express the leukocytic intercellular adhesion molecule-1 (ICAM-1) $[8,9]$ as well as caveolin, a structural protein of caveolae, and antigens recognized by other type I cell-specific monoclonal antibodies [10-12]. One of the type I cell-specific monoclonal antibodies recognizes a 40-42 $\mathrm{kDa}$ apical plasma membrane integral protein (RTI40) that was detected in the alveolar fluid of injured lungs [13]. Another type I cellspecific monoclonal antibody is MEP-1 [14-16].

In the present study, the distribution of RTI40, MEP-1 antigen and the BPA lectin-binding glycoprotein was investigated in bleomycin-injured rat lungs and compared with that in normal adult and foetal lung tissue. The binding to the alveolar surface has been shown to be stable even under conditions of lung injury, compared with the immunoreactions of antibodies against type I cell-specific antigens $[7,12]$.

\section{Materials and methods}

Male Wistar rats weighing 350-400 g were given a single dose of 7 units of bleomycin sulphate in phosphatebuffered saline (PBS) $\cdot \mathrm{kg}$ body weight ${ }^{-1}$ by intratracheal instillation. Controls received PBS alone. Different animals were killed at 7, 14, 21, 28, 35 and 42 days after bleomycin application and the lungs were prepared and lavaged via the trachea with PBS [17].

Sections of formalin-fixed, paraffin-embedded lung tissue (normal, $n=5$; injured tissue, 4 weeks after bleomycin administration, $\mathrm{n}=12$ ) were dewaxed. In addition, sections 
of foetal lung ( $\mathrm{n}=2 ; 19$ and 20 days postconception) were used.

The immunohistochemical procedures have been described previously $[16,18]$. In brief, all sections (no enzymic or other pretreatment, consecutive serial sections) were treated with $0.3 \%$ hydrogen peroxide in methanol for 30 min. Nonspecific protein binding was blocked by $10 \%$ horse serum. The sections were incubated with primary antibodies (MEP-1, dilution 1:50; anti-RTI40, dilution 1: $100)$, and in some additional cases for control purposes with the antibody Ks18.04 against cytokeratin 18 (Progen, Heidelberg, Germany; dilution 1:80) for $45 \mathrm{~min}$ at $25^{\circ} \mathrm{C}$. The sections were rinsed with PBS and incubated with biotinylated horse antimouse immunoglobulin (Vector Laboratories; distributed by Camon, Wiesbaden, Germany) for $1 \mathrm{~h}$, washed extensively, incubated with avidin-biotinperoxidase complex for $1 \mathrm{~h}$, developed with diaminobenzidine and counterstained with haematoxylin.

Double-label immunofluorescence was employed for the simultaneous detection of BPA binding (biotinylated lectin from Vector Laboratories, dilution 1:400) and for the binding of the antibody to RTI40 [7, 19]. Negative controls were performed by replacement of the primary antibody by either PBS or a monoclonal antibody specific for a protein of the cilia of the bronchial epithelium and the mesothelium [20].

\section{Pre-embedding immunoelectron microscopy}

For immunoelectron microscopy, 2-3- $\mathrm{mm}^{3}$ pieces of normal and injured rat lungs were fixed in cacodylatebuffered $4 \%$ paraformaldehyde with $0.12 \%$ glutaraldehyde for $2 \mathrm{~h}$ and incubated in the same buffer containing $20 \%$ sucrose overnight at $4^{\circ} \mathrm{C}$. After washing in buffer, vibratome sections were cut. The pre-embedding procedure has been described previously [17]. In brief, sections of 100 $\mu \mathrm{m}$ thickness were exposed to $10 \%$ goat serum for $30 \mathrm{~min}$ and washed twice in $150 \mathrm{mM}$ Tris- $\mathrm{HCl}, \mathrm{pH} \mathrm{8.2,} \mathrm{contain-}$ ing $140 \mathrm{mM} \mathrm{NaCl}$ (Tris-buffered saline (TBS)), $0.2 \%$ bovine serum albumin (BSA) and $0.2 \%$ Triton X-100 for 5 min at $25^{\circ} \mathrm{C}$. Sections were exposed to the primary monoclonal antibody against RTI40 overnight at $4{ }^{\circ} \mathrm{C}$ and for $2 \mathrm{~h}$ at $25^{\circ} \mathrm{C}$. As a negative control, the primary antibody was replaced by TBS. After washing in TBS, the sections were placed in $18 \mathrm{~nm}$ gold-coupled goat antimouse immunoglobulin (Dianova, Hamburg, Germany). The postfixation was performed using $1 \% \mathrm{OsO}_{4}$ in $0.2 \mathrm{M}$ phosphate buffer for $2 \mathrm{~h}$. The sections were dehydrated using acetone in increasing concentrations and then embedded in Vestopal (Serva, Heidelberg, Germany). Ultrathin sections were double-stained with $2 \%$ uranyl acetate and $1 \%$ lead citrate. For microscopy, a Zeiss EM 900 electron microscope (Zeiss, Oberkochen, Germany) was used at a voltage of 80 $\mathrm{kV}$.

\section{Western blot and semiquantitative dot blot of RTI4O}

For Western blot of RTI40, the proteins from $15 \mathrm{~mL}$ of bronchoalveolar fluid were precipitated by ultracentrifugation at $100,000 \times g$ at $4^{\circ} \mathrm{C}$ for $2 \mathrm{~h}$ and redissolved in 50 $\mu \mathrm{L} 360 \mathrm{mM}$ Tris, $\mathrm{pH}$ 6.8, containing $190 \mathrm{mM}$ sodium dodecyl sulphate, $0.03 \%$ bromphenol blue and $55 \%(\mathrm{v} / \mathrm{v})$ glycerol. Then, $10 \mu \mathrm{L}$ of the protein solution was subjected to polyacrylamide gel electrophoresis under reducing conditions. After transfer of the proteins to a nitrocellulose membrane and blocking of nonspecific binding using $5 \%$ nonfat milk in TBS, pH 7.6, detection of RTI40 was performed with the monoclonal antibody against RTI40 (purified immunoglobulin (Ig) G from hybridoma supernatant, dilution 1:500) as the primary antibody and horseradish peroxidase-conjugated antimouse immunoglobulin (New England Biolabs, Schwalbach/Taunus, Germany) as the secondary antibody. The blots were developed with luminol reagent and hydroperoxide (enhanced chemiluminescence (ECL) New England Biolabs) and exposed to Hyperfilm (ECL; Amersham, Braunschweig, Germany). The dark bands were analysed by densitometry.

For semiquantitative dot blot, proteins of the bronchoalveolar fluid (two bleomycin-treated rats, 28 days after treatment, and two controls) were precipitated by the addition of solid ammonium sulphate (final concentration $4.9 \mathrm{M}$ ), collected by centrifugation at $25,000 \times g$ at $4^{\circ} \mathrm{C}$ for $30 \mathrm{~min}$ and redissolved in PBS. The dot blot was performed as described previously [13]. RTI40 was detected using the monoclonal antibody against RTI40 (undiluted hybridoma supernatant) as the primary antibody, horseradish peroxidase-conjugated sheep antimouse immunoglobulin as the secondary antibody and ECL reagents (Amersham) for development. Quantitation was performed by measurement of light emission in a plate luminometer (Packard Instruments, Downers Grove, IL, USA). A standard curve was performed using normal rat lung homogenates to ascertain the linear range of the assay. The amount of RTI40 was expressed in arbitrary units.

\section{Results}

Changes in the localization of RTI40 protein, MEP-1 antigen and the BPA binding glycoprotein in rat lung tissue during the development of pulmonary fibrosis were studied by immunohistochemical techniques.

In adult lung, the antibody to RTI40 stained the type I alveolar epithelial cells (fig. 1B). Some epithelial cells at the surface of developing alveoli in foetal rat lung were also stained (fig. 1A). The bronchial epithelium and the pleura mesothelium were devoid of staining. Immunoelectron microscopy of normal lung confirmed the type I cell specificity of the antibody to RTI40 (fig. 2). In some cases alveolar macrophages showed weak labelling of the microvilli opposite to the alveolar surface (fig. 3).

Twenty-eight days after intratracheal administration of bleomycin, lung tissue showed morphological evidence of pulmonary fibrosis with focal thickening of the alveolar walls, increased interstitial cellularity and enhanced matrix deposition. Hypertrophic and hyperplastic type II pneumocytes and alveolar macrophage clusters were seen in fibrotic foci. Mild peribronchiolar inflammation was also seen.

In fibrotic foci of lung tissue, areas of alveolar lining lacking immunostaining for RTI40 were seen (fig. 1D). Consecutive serial sections, however, showed that these areas were still positive for MEP-1 (fig. 1C). In particular, alveoli with signs of obliteration were MEP-1 positive/ RTI40 negative (fig. 1C and D). 

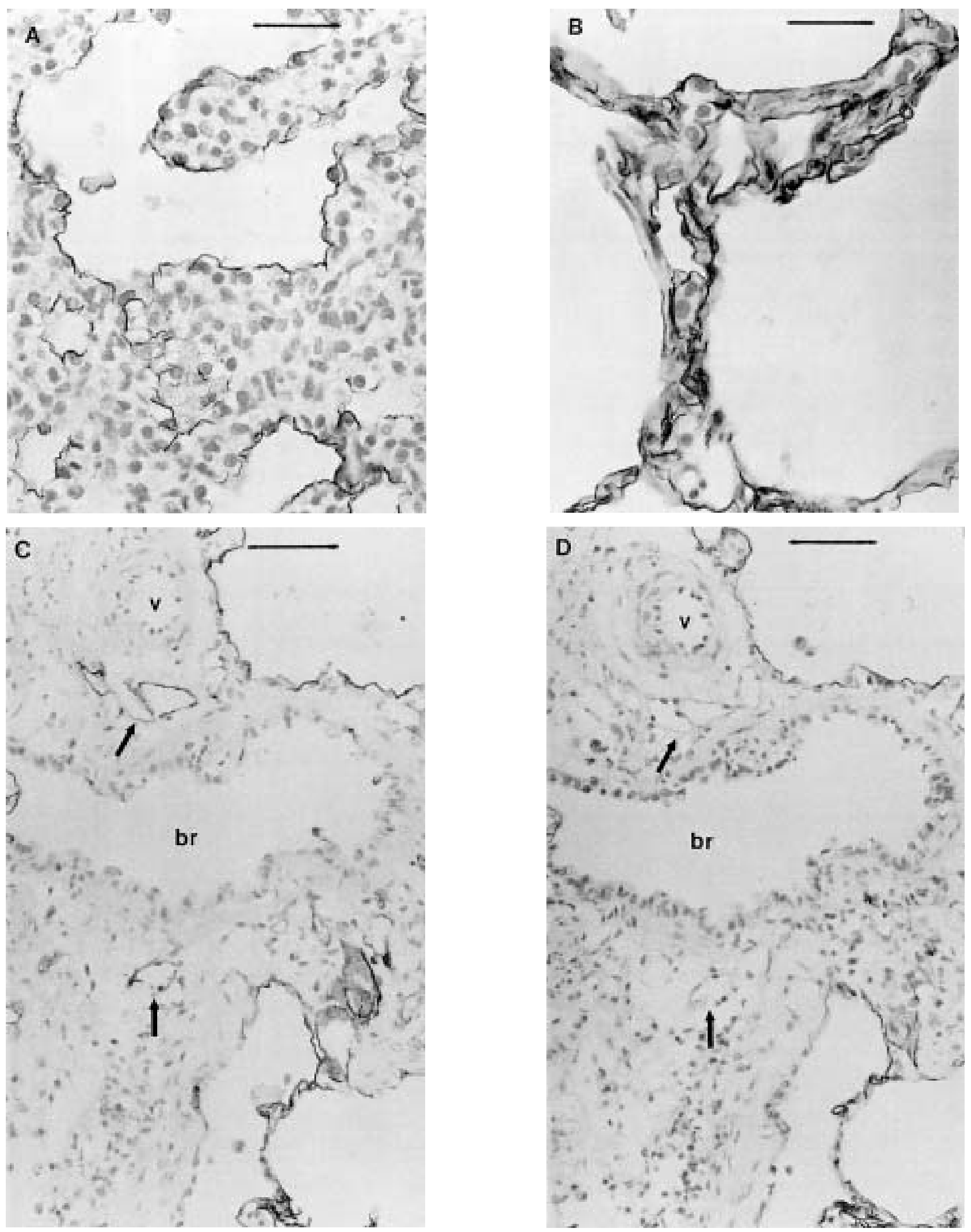

Fig 1. - Paraffin sections of rat lung. Demonstration of the staining for RTI40 antigen (A, B, D) and for MEP-1 antigen (C) in foetal (A, day 19), normal adult (B) and in fibrotic tissue (C and D are consecutive serial sections) by the immunohistochemical technique. In foetal lung tissue, the surface of primitive alveoli is stained with anti-RTI40 (A). Staining of type I pneumocytes with anti-RTI40 in normal adult rat lung (B). In the fibrotic tissue (D), focal loss of staining can be seen (small arrows). Comparison of consecutive serial sections (C: MEP-1 staining; D: RTI40 deposition) shows the loss of RTI40 in obliterating alveoli (small arrows in C, D). v: blood vessel lumen; br: terminal bronchiole. (Internal scale bars $=50 \mu \mathrm{m}(\mathrm{A}, \mathrm{B}) ; 100 \mu \mathrm{m}$ $(\mathrm{C}, \mathrm{D})$.) 

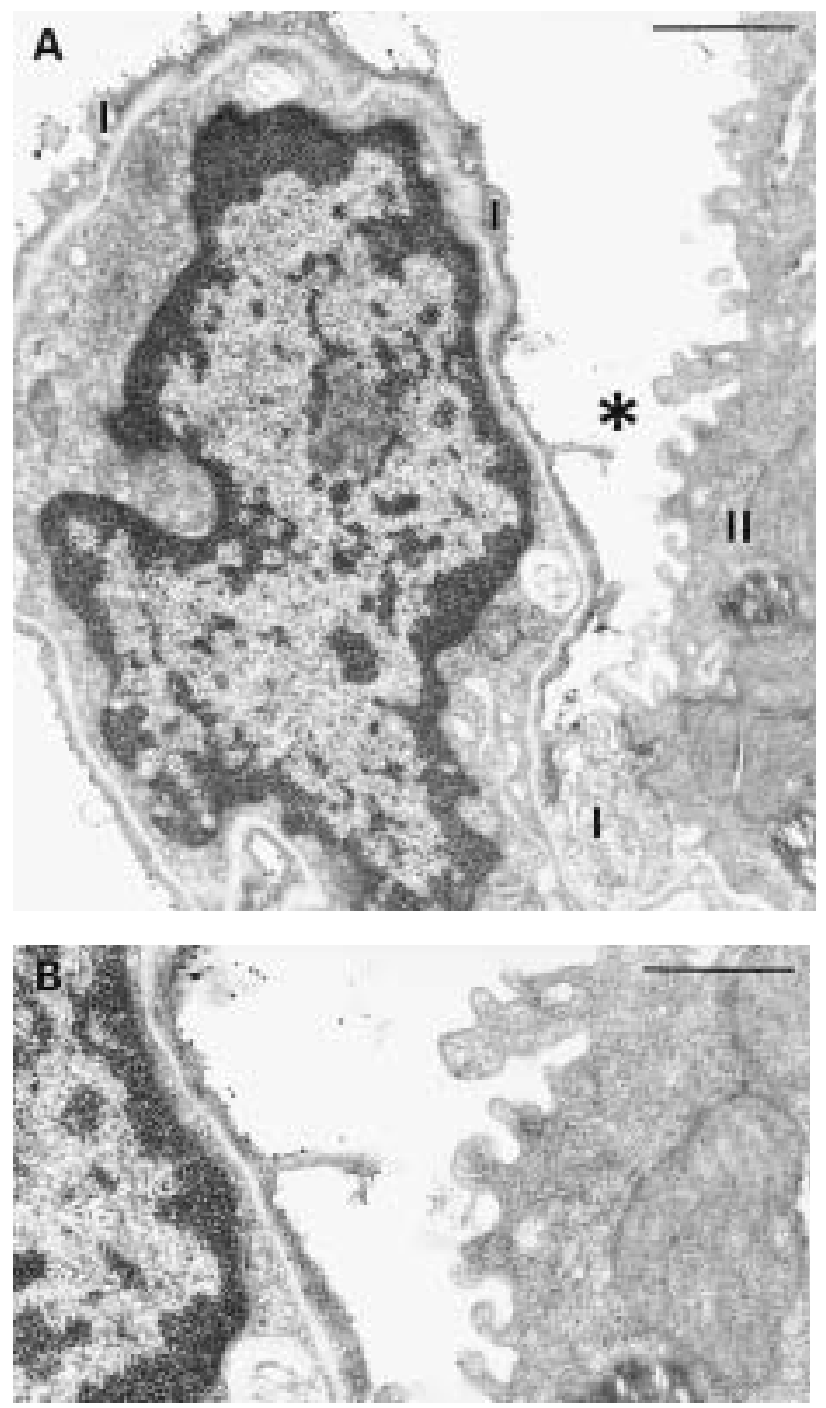

Fig. 2. - Immunogold labelling of RTI40 in normal rat lung tissue. A) The surface of a type I pneumocyte (I) is labelled. The microvilli of the neighbouring type II pneumocyte (II) are not labelled for RTI40. B) Higher magnification of the area indicated by an asterisk in A. (Internal scale bars $=1 \mu \mathrm{m}(\mathrm{A}) ; 0.67 \mu \mathrm{m}(\mathrm{B})$.)

Similarly, loss of RTI40 immunoreactivity was found in double-label fluorescence experiments with BPA, a recently detected type I cell-binding lectin [7] (fig. 4). Immunoelectron microscopy revealed focal lack of immunogold labelling at the alveolar epithelial surface and association of gold particles with extracellular material (fig. 5A-C).

Loss of RTI40 protein bound to the surface of type I epithelial cells was accompanied by an increasing level of RTI40 in the bronchoalveolar fluid (fig. 6). Densitometric evaluation of Western blot analysis revealed an increase in the RTI40 level in the bronchoalveolar fluid by about three-fold at days 7 and 14 after bleomycin administration. After that, the RTI40 level decreased and reached control levels 42 days after bleomycin administration.

The bronchoalveolar fluid of control rats contained (mean \pm SD) $81 \pm 0 \mathrm{U} \mathrm{RTI} 40 \cdot \mathrm{mg}$ protein ${ }^{-1}$, as determined by semiquantitative dot blot; that of bleomycin-treated animals (28 days) contained $242 \pm 56 \mathrm{U} \cdot \mathrm{mg} \operatorname{protein}^{-1}(\mathrm{n}=2)$.

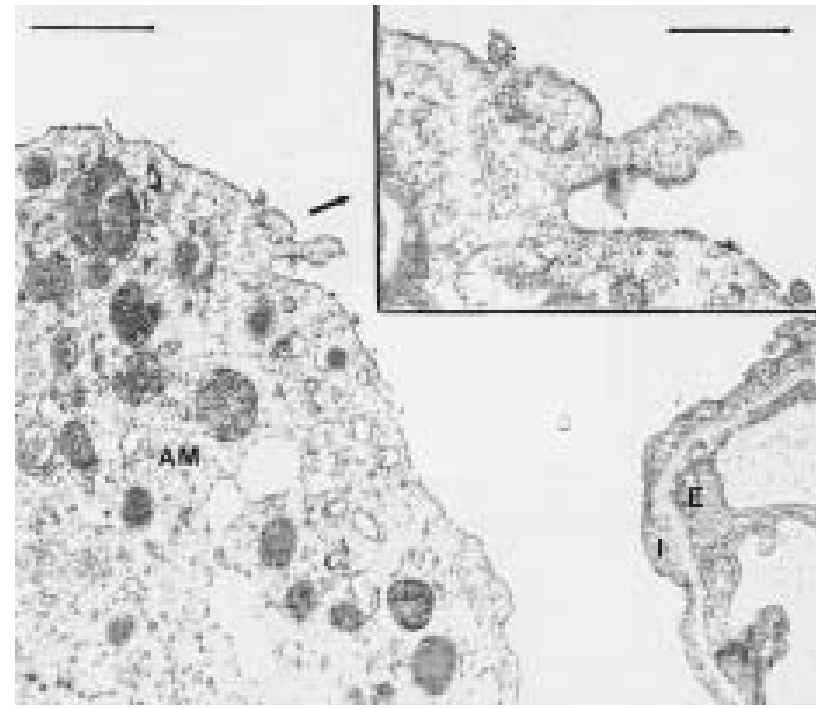

Fig. 3. - An alveolar macrophage (AM) in fibrotic lung showing RTI40 protein at the surface. (Internal scale bars $=1 \mu \mathrm{m}(\mathrm{A}) ; 0.38 \mu \mathrm{m}$ (inset).)

The molecular mass of the RTI40 protein was determined to be approximately $40 \mathrm{kDa}$.

\section{Discussion}

Loss of RTI40 protein from the alveolar surface of obliterating alveoli during the development of pulmonary fibrosis following bleomycin administration to rats is described for the first time in this paper. An immunohistochemical technique on consecutive serial sections was employed using the type I cell-specific monoclonal antibody MEP-1 specific for a $36 \mathrm{kDa}$ protein $[14,15]$. The monoclonal antibody against RTI40 has already been used as a type I cell marker during development of foetal rat lung [21]. RTI40 has also been shown to be a biochemical marker of epithelial injury in Pseudomonas aeruginosainduced pneumonia in the rat [13]. RTI40 was found to be increased in the bronchoalveolar fluid of injured rat lungs after instillation of $P$. aeruginosa into the lungs; its level in the bronchoalveolar fluid correlated with the degree of damage to type I epithelial cells [13]. Elevated amounts of RTI40 in the bronchoalveolar fluid were also found during lung injury caused by sublethal hyperoxia or $\mathrm{NO}_{2}[22,23]$.

In the present study, the antibody against RTI40 was applied successfully to microwaved paraffin sections of routinely formalin-fixed tissues. Elevated levels of RTI40 were found in the bronchoalveolar fluid after intratracheal administration of bleomycin. The increased RTI40 level in the bronchoalveolar fluid found on days 7 and 14 indicates severe epithelial injury. The subsequent decrease in the RTI40 level might be due to re-epithelialization processes. These results resemble those of a previous study by KASPER et al. [17], in which the type I cell-specific adhesion molecule ICAM-1 was demonstrated to be lost from the alveolar epithelial surface and to be present in the bronchoalveolar fluid of bleomycin-treated rats. The distribution of RTI40 protein and BPA-lectin binding glycoproteins on the surface of type I epithelial cells in the 

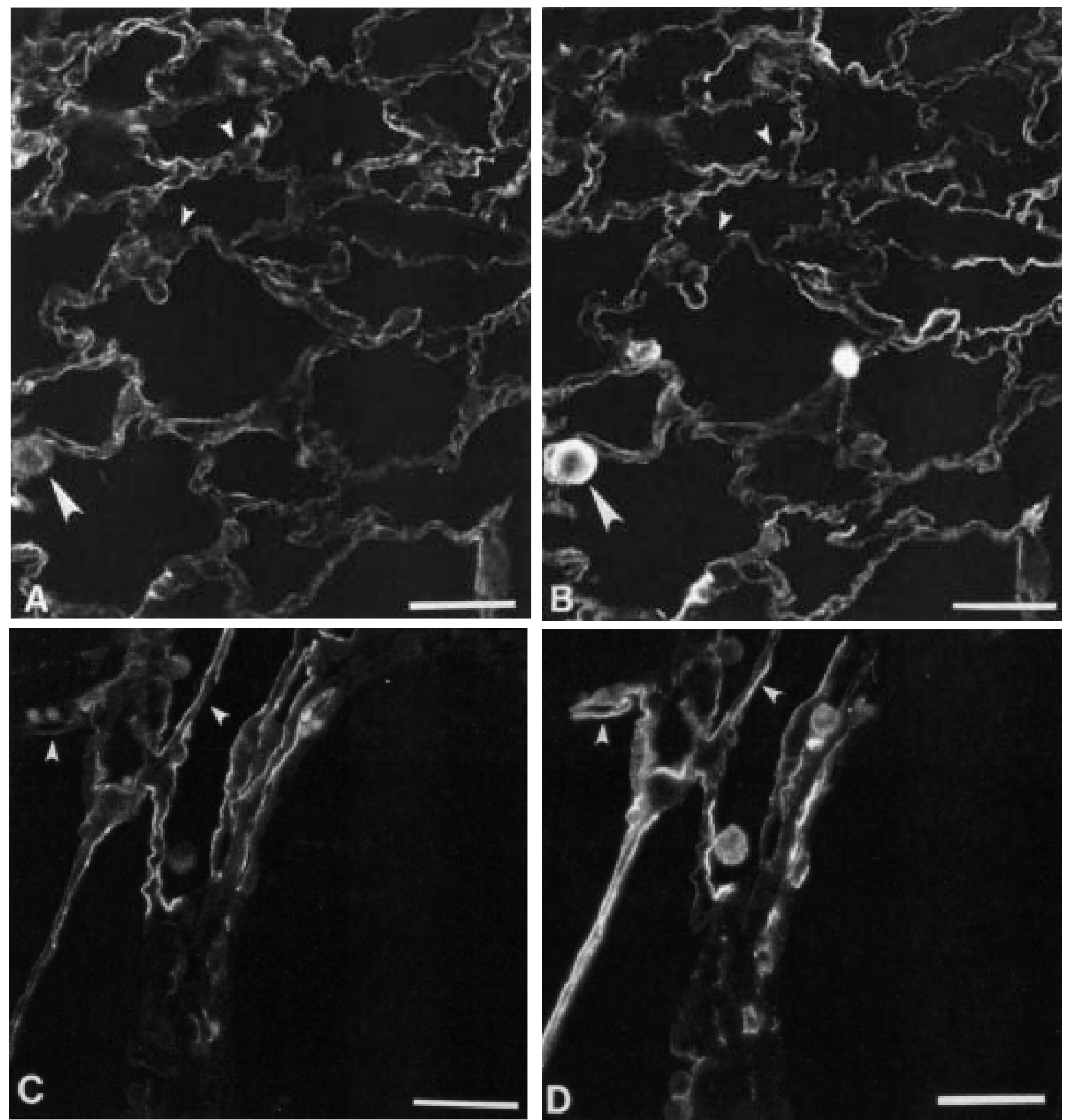

Fig. 4. - Double-label immunofluorescence detection of the RTI40 protein (A, C) and of Bauhinia purpurea agglutinin (BPA) lectin-binding protein (B, D) in normal (A, B) and fibrotic (C, D) rat lung tissue. Small arrowheads in A and B show negative type II pneumocytes. The large arrowhead in A and B indicates a BPA-positive/RTI40-negative alveolar macrophage. Small arrowheads in C and D indicate the loss of RTI40 protein compared with the corresponding lectin binding to the alveolar surface of fibrotic lung tissue. (Internal scale bars $=50 \mu \mathrm{m}$.)

fibrotic rat lung differs from that in normal lung tissue [7]. BPA-lectin is specific for type I cells and for alveolar macrophages. The presence of type I cell markers such as MEP-1 antigen and BPA lectin binding glycoprotein in RTI40 negative areas, the immunoelectron microscopical data and the three-fold elevated levels of RTI40 in the bronchoalveolar fluid of bleomycin-treated rats indicate real loss of RTI40 from the epithelial cell surface, despite evidence in the literature for incomplete transformation of type II pneumocytes into type I cells in pulmonary fibrosis [24].

In contrast to loss or shedding of certain alveolar epithelial surface antigens during remodelling processes in pulmonary fibrosis, some lectin binding studies revealed changes in the glycoconjugate composition of type I cells [25]. Moreover, there is evidence that during the development of pulmonary fibrosis the alveolar epithelial surface can be ligated by galectin-3, the endogenous lectin of 

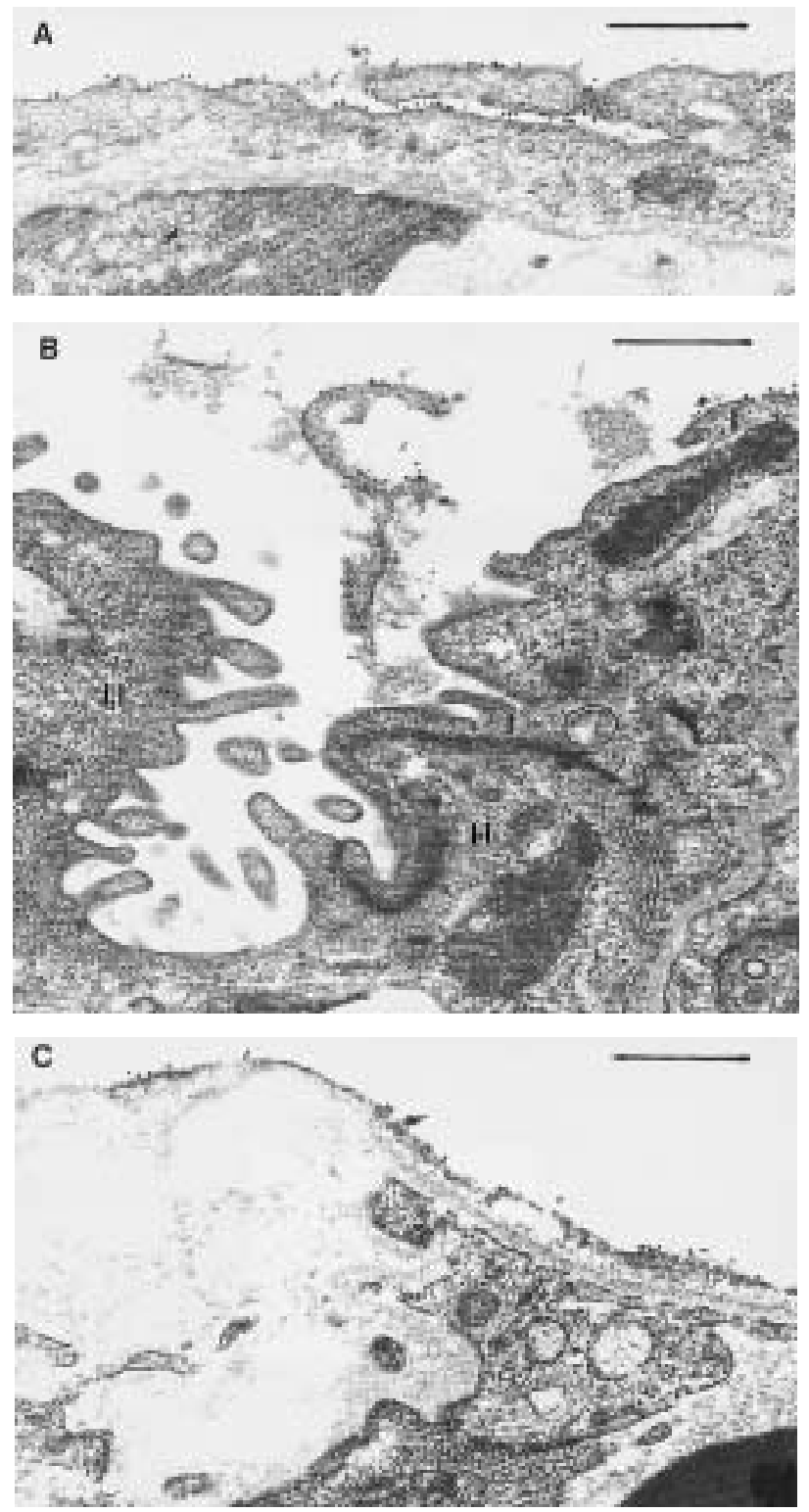

Fig. 5. - Immunogold labelling of RTI40 in fibrotic rat lung tissue. Note the discontinuous gold labelling $(10 \mathrm{~nm}$ gold $)$ on the alveolar epithelium (A, C) and on cell debris (B) in fibrotic lungs (I: type I pneumocyte; II: type II pneumocyte). (Internal scale bars $=0.57 \mu \mathrm{m}$.)

alveolar macrophages, thus leading to altered surface properties of the alveolar epithelium [26].

In conclusion, bleomycin-induced lung injury in rat results in selective loss of RTI40 protein from the cell surface of type I pneumocytes. This study demonstrates that the determination of RTI40 protein in the bronchoalveolar fluid of rats after intratracheal administration of bleomycin is a useful semiquantitative method by which to assess injury to the alveolar epithelium. The significant phenotypic changes in the alveolar epithelial surface during the development of pulmonary fibrosis may be discussed in terms of altered fluid transport or altered cell-cell interaction.

Acknowledgements: The authors thank P. Peche, R. Gonzales and S. Langer for excellent technical assistance. a)

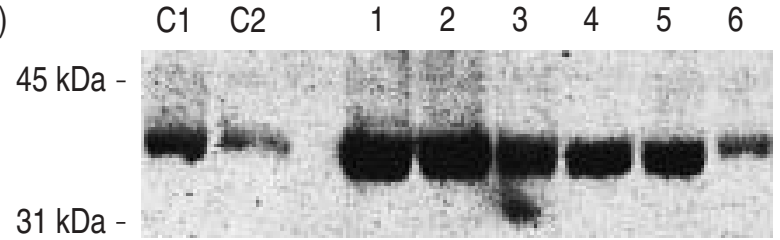

b)

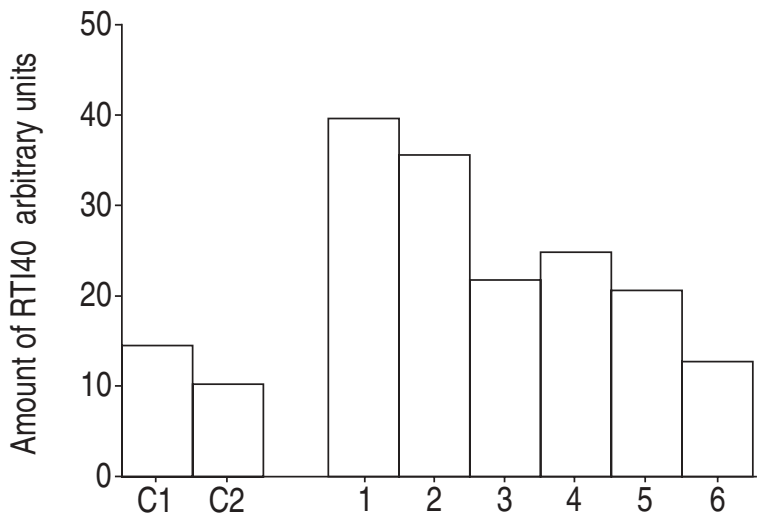

Fig. 6. - a) Western blot analysis of soluble RTI40 protein in the bronchoalveolar fluid (one representative blot) and b) quantitation by densitometry. C1 and C2: two controls. Lanes 1-6: RTI40 protein detected by the monoclonal antibody against RTI40 in the bronchoalveolar fluid of bleomycin-treated rats at days $7,14,21,28,35$ and 42 post-treatment respectively.

\section{References}

1. Kasper M, Singh G. Epithelial lung cell marker: current tools for cell typing. Histol Histopathol 1995; 10: 155169.

2. Funkhouser JD, Peterson RDA. Immunotargeting: a contemporary approach to the study of lung development. Am J Physiol 1989; 257: L311-L317.

3. Kasper M, Höfer D, Woodcock-Mitchell J, et al. Colocalization of cytokeratin 18 and villin in type III alveolar cells (brush cells) of the rat lung. Histochemistry 1994; 101: 57-62.

4. Höfer D, Drenckhahn D. Identification of brush cells in the alimentary and respiratory system by antibodies to villin and fimbrin. Histochemistry 1992; 98: 237-242.

5. Bankston PW, Porter GA, Milici AJ, Palade GE. Differential and specific labeling of epithelial and vascular endothelial cells of the rat lung by Lycopersicon esculentum and Griffonia simplicifolia I lectins. Eur J Cell Biol 1991; 54: 187-195.

6. Taatjes DJ, Barcomb LA, Leslie KO, Low RB. Lectin binding patterns to terminal sugars of rat lung alveolar epithelial cells. J Histochem Cytochem 1990; 38: $233-$ 244.

7. Kasper M, Schuh D, Müller M. Bauhinia purpurea lectin (BPA) binding of rat type I pneumocytes: alveolar epithelial alterations after irradiation-induced lung injury. Exp Toxic Pathol 1994; 46: 361-367.

8. Christensen PJ, Kim S, Simon RH, Toews GB, Paine R. Differentiation-related expression of ICAM-1 by rat alveolar epithelial cells. Am J Respir Cell Mol Biol 1993; 8: 9-15.

9. Kang BH, Crapo JD, Wegner CD, Letts LG, Chang LY. Intercellular adhesion molecule-1 expression on the alveolar epithelium and its modification by hyperoxia. Am J Respir Cell Mol Biol 1993; 9: 350-355. 
10. Dobbs LG, Williams MC, Gonzalez R. Monoclonal antibodies specific to apical surfaces of rat alveolar epithelial cells bind to surfaces of cultured, but not freshly isolated type II cells. Biochim Biophys Acta 1988; 970: 146-156.

11. Danto SI, Zabski SM, Crandall ED. Late appearance of a type I alveolar epithelial cell marker during fetal rat lung development. Histochemistry 1994; 102: 297-304.

12. Kasper M, Reimann T, Hempel U, et al. Loss of caveolin expression in type I pneumocytes as an indicator of subcellular alterations during lung fibrogenesis. Histochem Cell Biol 1998; 109: 41-48.

13. McElroy MC, Pittet JF, Hashimoto S, Allen L, WienerKronish JP, Dobbs LG. A type I cell-specific protein is a biochemical marker of epithelial injury in a rat model of pneumonia. Am J Physiol 1995; 268: L181-186.

14. Tsuchiya T, Takeya M, Takagi K, Takahashi K. Production of monoclonal antibody (MEP-1) against fibroblastlike cells of rat malignant fibrous histiocytoma. J Clin Electron Microscopy 1990; 23: 5-6.

15. Tsuchiya T, Takahashi K, Takeya M, Hosokawa Y, Hattori $\mathrm{T}$, Takagi $\mathrm{K}$. Immunohistochemical, quantitative immunoelectron microscopic, and DNA cytofluorometric characterization of chemically induced rat malignant fibrous histiocytoma. Am J Pathol 1993; 143: 431-445.

16. Kasper M, Takeya M, Takahashi K, Grossmann H, Schuh D, Müller M. Immunohistochemistry of new type I alveolar epithelial cell markers of the rat. Histol Histopathol 1996; 11: 145-152.

17. Kasper M, Koslowski R, Luther T, Schuh D, Müller M, Wenzel K-W. Immunohistochemical evidence for loss of ICAM-1 adhesion molecule by alveolar epithelial cells in pulmonary fibrosis. Histochem Cell Biol 1995; 104: 397405.

18. Kasper M, Fuller SD, Schuh D, Müller M. Immunohistological detection of the beta subunit of prolyl 4-hydroxy- lase in rat and mini pig lungs with radiation-induced pulmonary fibrosis. Virchows Arch 1994; 425: 513-519.

19. Kasper M, Sakai K, Koslowski R, et al. Localization of surfactant protein A (SP-A) in alveolar macrophage subpopulations of normal and fibrotic lung. Histochemistry 1994; 102: 345-352.

20. Singh G, Singh J, Ordonez NG, et al. Expression of a 130-kDa mesothelial and ciliated cell antigen (MCp130) in normal and developing human and rat lung and its role as a diagnostic marker for mesotheliomas and tumors of the female reproductive system. Lab Invest 1995; 73: 48 58 .

21. Williams MC, Dobbs LG. Expression of cell-specific markers for alveolar epithelium in fetal rat lung. Am J Respir Cell Mol Biol 1990; 2: 533-542.

22. McElroy MC, Wiener-Kronish JP, Miyazaki $\mathrm{H}$, et al. Nitric oxide attenuates lung endothelial injury caused by sublethal hyperoxia in rats. Am J Physiol 1997; 272: L631-L638.

23. McElroy MC, Pittet JF, Allen L, Wiener-Kronish JP, Dobbs LG. Biochemical detection of type I cell damage after nitrogen dioxide-induced lung injury in rats. Am J Physiol 1997; 273: L1228-1234.

24. Simon RH, Paine R. Participation of pulmonary alveolar epithelial cells in lung inflammation. J Lab Clin Med 1995; 126: 108-118.

25. Schulte BA, Harley RA, Spicer SS. Carbohydrate histochemistry. In: Gil J, ed. Models of Lung Disease: Microscopy and Structural Methods. Lung Biology in Health and Disease Series. New York, Marcel Dekker, 1990; pp. 147-159.

26. Kasper M, Hughes RC. Immunocytochemical evidence for a modulation of galectin 3 (Mac-2), a carbohydrate binding protein, in pulmonary fibrosis. J Pathol 1996; 179: 309-316. 